\title{
TIEMPOS Y FORMAS VERBALES EN LA PRODUCCIÓN ORAL DE UN GRUPO DE PREESCOLARES Y ESCOLARES DE PRIMER AÑO BÁSICO*
}

\section{Claudine Benoit Ríos**}

\section{Resumen}

El presente trabajo da cuenta de los tiempos verbales que utiliza un grupo de niños en la narración de breves historias y de qué formas se vale para su expresión o desarrollo lingüísticos. La hipótesis está en directa relación con el hecho de que el niño utiliza, de preferencia, los tiempos presente y pretérito, y las formas verbales simples; el uso del futuro, por su parte, es escaso en ambos grupos del estudio (Gili Gaya, 2000; Sánchez et al., 2010). La muestra estuvo conformada por diez niños de una escuela en riesgo social, separados en dos grupos de edades: el primero, de 4,6 a 4,11 años y el segundo, de 6,6 a 7 años. Los resultados apoyan la hipótesis, pues el grupo A (más pequeño) evidenció en su producción oral un mayor uso del tiempo presente; en cambio, el grupo B utilizó preferentemente el tiempo pretérito. En ambos grupos, la utilización del futuro y de las formas verbales compuestas fue escasa.

Palabras clave: desarrollo, lenguaje, morfología, producción, verbos.

\section{FRESHMEN ELEMENTARY SCHOOL CHILDREN AND THEIR ORAL SPEECH VERB TENSES}

\begin{abstract}
The following research deals with verbs tenses that a group of children has used and the ways the use of verbs is justified for their linguistic development. The hypothesis is based on the fact that children mainly use simple present and simple past verb tenses in their language exchange; and the fact that there should be a lack of future tense for communication in the group of study (Gili Gaya, 2000; Sánchez et al., 2010). The participants were gathered from a lower social group of children. They were separated by age groups. The first group is $4-6$ to 4-11 years old and the second is 6,6 to 7 years old. The results support our hypothesis since group A (lower age group) showed higher use of present tense regarding oral production. On the contrary, group B (higher age group) used past tense when describing the tale story. The future tense and phrasal verbs were both barely used by subjects.
\end{abstract}

Key words: language development, morphology, language exchange, verbs.

Recibido: 30-10-2012

Aceptado: 16-04-2013

\footnotetext{
* Este artículo es parte de la fase piloto de estudios de Doctorado en la Universidad de Concepción, con apoyo de beca CONICYT.

** Chilena, Doctora en Lingüística, Universidad de Concepción, Concepción, Chile. cbenoi@@udec.cl
} 


\section{Introducción}

El desarrollo del lenguaje en el niño está estrechamente vinculado con las ideas de cambio, evolución y enriquecimiento. En sus primeras etapas, el niño está en búsqueda del saber, de la exploración, del tocar, del exponer, lo que, llevado al plano lingüístico, lo configura como un ente activo del proceso de comprensión, producción y creación. Esta es la motivación principal para el desarrollo de esta investigación, es decir, abordar un tema tan dinámico como es el de los tiempos verbales y ver qué ocurre en etapas que van desde los cuatro a los siete años, aproximadamente.

\subsection{Algunos aspectos sobre el desarrollo cognitivo- lingüístico desde los 4 a los 7 años}

Según Piaget (1986), en esta etapa el niño se encuentra en el estadio del pensamiento preoperatorio o prelógico, que se caracteriza por el hecho de que cada niño se descentra -deja el egocentrismo- y pasa de la coordinación de acciones al lenguaje o lógica verbal. Siguiendo sus planteamientos, el niño se encuentra en una fase de abandono del lenguaje utilizado sólo en función de él, para dar paso a una búsqueda de la sociabilización lingüística (Piaget, 1986, 31-61).

Por su parte, López Ornat (1999) sostiene que el niño a esta edad se encuentra en una fase de gramaticalización temprana, caracterizada por el hecho de que tanto los ejemplares lingüísticos categorizados como los principios de categorización mismos devienen gramaticales. Desde esta perspectiva, las categorías gramaticales son más estables, discretas, absolutas y axiomáticas que las categorías pregramaticales, y "esos rasgos son un requisito imprescindible para el procesamiento automático y no atendido que demanda un sistema cognitivo adulto" (López Omat, 1999, 509).

En el desarrollo lingüístico del niño en esta etapa se evidencia una utilización bastante consistente de los elementos gramaticales fundamentales que le permiten un uso pragmático del lenguaje. Según Echeverría (1978), la razón de esto estaría en el hecho de que el ser humano está provisto de una capacidad lingüística innata que le permite procesar los estímulos verbales a los que se encuentra expuesto para llegar así a formular un constructo teórico que se denomina "gramática

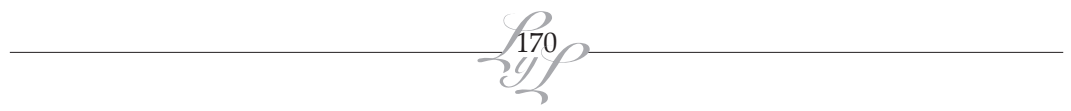


mental o gramática universal"1 ${ }^{1}$ Esta gramática mental o sistema de reglas lingüísticas, según algunos psicólogos, sería la que construiría, al internalizarse a través de la infancia, "las estructuras básicas del pensamiento"; en palabras de Vygotski (1962), el lenguaje internalizado sería la base del pensamiento (citado en Echeverría, 1984, 19).

De acuerdo con aquella disposición innata, Karmiloff-Smith (1994) señala que, en la búsqueda de su aprendizaje, el niño fusiona lo innato y lo propio de su desarrollo, entendiendo de esta forma que el lenguaje necesita de lo predeterminado y de la construcción activa y dinámica que realiza cada infante en el afianzamiento de su expresión comunicativa. Según la autora, la perspectiva del desarrollo es esencial para el análisis del conocimiento humano, para comprender la arquitectura preestablecida de la mente del niño, las restricciones del aprendizaje y cómo cambia el conocimiento progresivamente a lo largo del tiempo (Karmiloff-Smith, 1994, 46). Aitchison (1992), por su parte, intenta mostrar que el lenguaje comparte las características de las conductas biológicamente programadas, esto es, surge antes de que sea necesario y su aparición no puede explicarse ni por sucesos externos ni por decisiones voluntarias del niño. Según el autor, existe un mecanismo interno que desencadena y regula el desarrollo del lenguaje y, al mismo tiempo, debe afianzarse en una estimulación externa para funcionar correcta y enriquecedoramente (Aitchison, 93-122). Según Vygotski, la función inicial del lenguaje es la de comunicación, es un lenguaje socializado, de conexión social, de influencia con el entorno; en este punto, discrepa Piaget, pues señala que el lenguaje inicial del niño es solamente social y que no es correcto llamarlo socializado, "porque implica la idea de un lenguaje originalmente no social que se hace social a lo largo del proceso de cambio y desarrollo" (57).

Para abordar el tema de los tiempos verbales en este estudio, se adopta la concepción acerca de que el niño mantiene una disposición innata para el lenguaje, pero, al mismo tiempo, de que es evidenciable un comportamiento lingüístico evolutivo que permite hablar con propiedad de desarrollo².

1 Chomsky (1965) presentó una serie de argumentos para hablar de un componente sintáctico innato de la facultad del lenguaje, necesario para la adquisición del lenguaje en los niños y de un almacén de competencia lingüística de los adultos.

2 Parisse (2005) presenta en su trabajo perspectivas relativamente actuales acerca del desarrollo del lenguaje y del carácter innato del conocimiento gramatical. 


\subsection{Los tiempos verbales, según Gili Gaya (2000)}

La investigación presentada tuvo como uno de sus fundamentos la teoría general de los verbos establecida por Gili Gaya $(2000)^{3}$. Por ser de interés para el presente estudio, se pondrá el foco en los principales tiempos verbales y en algunos rasgos que, por investigaciones previas (Peronard, 1981; Pandolfi, 1988), son los que se puede observar en los niños durante estas etapas: tiempo presente, pretéritos, futuros, condicionales y algunos tiempos del subjuntivo.

Según la teoría acerca de los tiempos verbales, el presente del modo indicativo expresa las acciones que coexisten con el acto de la palabra. Tal como lo sostiene Gili Gaya (2000), el tiempo presente es como un punto de movimiento, que viene del pasado y marcha hacia el porvenir; por ello, raras veces la acción expresada por el presente coincide estrictamente con el acto de enunciarla, sino que ha comenzado antes y continúa después.

El pretérito perfecto absoluto es utilizado para expresar las acciones pasadas independientes de cualquier otra acción; "es por la forma absoluta del pasado" (Gili Gaya, 2000, 157). Según el mismo autor, el pretérito imperfecto es relevante por el hecho de que la acción pasada "nos interesa sólo en su duración y no en su principio ni en su término". El antepretérito es un tiempo relativo que expresa una acción pasada a otra también pasada: "apenas hubo terminado se levantó", en este caso, los dos pretéritos se suceden inmediatamente. A diferencia de este tiempo, el pluscuamperfecto expresa la anterioridad con respecto a un hecho pasado y el futuro absoluto significa la acción venidera independientemente de cualquier otra acción. Principalmente por el carácter eventual de la acción que vendrá, el futuro absoluto está asociado, según Gili Gaya, a una cierta capacidad de abstracción por parte del enunciador (Gili Gaya, 2000, 145-204), lo que explicaría la ausencia casi total de este tiempo en las primeras etapas de desarrollo lingüístico de los niños.

En lo que respecta al modo subjuntivo, el autor señala que "el carácter de irrealidad que corresponde a las acciones expresadas en este modo, hace que las relaciones temporales de los distintos 'tiempos', o formas,

3 Gili Gaya (2000) clasifica los tiempos del modo indicativo en: presente, pretérito imperfecto, pretérito perfecto absoluto, pretérito perfecto actual, pluscuamperfecto, antepretérito, futuro absoluto, antefuturo, futuro hipotético y antefuturo hipotético. El modo imperativo, con su tiempo presente, y el modo subjuntivo, conformado por los tiempos presente, pretérito imperfecto, pretérito perfecto, pluscuamperfecto, futuro hipotético y antefuturo hipotético.

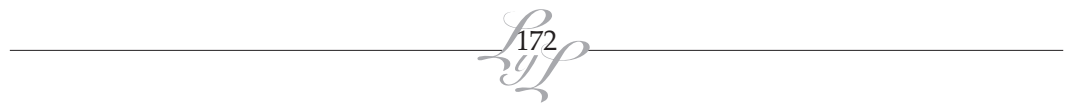


sean mucho menos claras que en el indicativo" (Gili Gaya, 2000, 175). Dado el carácter irreal del subjuntivo y el necesariamente eventual de las representaciones temporales del futuro, es natural que el presente y el futuro se confundan en una sola forma.

Las frases verbales o perífrasis, otro de los elementos lingüísticos considerados en el presente estudio, también desempeñan un papel importante en el lenguaje activo del niño, especialmente para referirse a situaciones durativas o a las que pasarán. El nombre de frases verbales fue propuesto por Seco (citado en Gili Gaya, 2000, 106) para designar a las perífrasis por el hecho de que están en correlación con las frases sustantivas, adjetivas, adverbiales, prepositivas y conjuntivas.

\subsection{Los tiempos verbales en los inicios del desarrollo lingüístico}

La morfología del verbo ha sido un tema de gran interés para los investigadores que han abordado el desarrollo lingüístico en sus primeras etapas (Ezeizabarrena, 2009; Barrière et al., 2010; Meisel, 1990; Pandolfi, 1988; Sebastián, 1989; Sebastián et al., 2004; Bernal et al., 2005). Estudiosos de diversas lenguas han puesto un acento especial en el contenido temporal de las formas verbales de pasado en el lenguaje infantil. De esta forma, nació la hipótesis 'aspecto antes que tiempo' (Andersen citado en Villamil, 1991, 212), que dio lugar a un dilatado debate entre autores que la apoyan y quienes no la comparten. En este sentido, López-Ornat (1994) aporta un dato empírico relativo a que la aparición de las formas de pasado sigue, según ella, este mismo orden: las perfectivas preceden a las imperfectivas, sin embargo, este resultado no es del todo representativo para el español de Chile.

En Chile, se dispone de poca investigación empírica que respalde o rechace la teoría acerca de qué tiempos son los que emplea el niño en una etapa concreta de su evolución. Un aporte a este ámbito es la investigación de Peronard (1981), quien realizó un estudio longitudinal de la expresión temporal de dos niños chilenos entre las edades de 1,7 a 3,0 años. Según sus hallazgos, en la edad más temprana, los niños utilizaron solamente verbos de actividad y, posteriormente, verbos desinentes; al igual que en otros estudios, sólo se utilizaron el presente y el imperfecto. De hecho, los primeros usos del imperfecto ocurrieron con los verbos de estado y, en los verbos desinentes, se encontraron también casi todas las formas 
del pretérito. El pretérito imperfecto apareció tardíamente; primero, con verbos de estado y, posteriormente, se generalizó a otros verbos. La presencia del imperativo, con su connotación de acción inminente, añade peso al concepto de temporalidad. Destaca, también, que los niños sí distinguen verbos de acuerdo con su contenido semántico, pero éste no es el único valor expresado, ya que utilizan formas verbales perfectivas (pretérito perfecto simple) con verbos imperfectivos (permanentes: actividad o estado). Peronard (1981) concluye que los niños manejan simultáneamente temporalidad y aspecto ${ }^{4}$.

Pandolfi (1988), con el objetivo de confeccionar un macroperfil sintáctico tentativo para detectar a través de él las estructuras gramaticales que el niño pequeño emplea en su producción espontánea, estudió a dos grupos de niños (grupo mayor, con un promedio de 2 años 8 meses, y un grupo menor, de un año 8 meses) y distinguió las siguientes formas verbales del modo indicativo: presente simple, pretérito perfecto, pretérito imperfecto y también el modo imperativo. Los resultados evidenciaron una preferencia por el presente simple en ambos grupos $(63 \%$, grupo mayor; $77 \%$, grupo menor) y una leve superioridad porcentual en el resto de las formas. En cuanto a las formas verbales compuestas observadas -futuro perifrástico- el grupo mayor superó al menor en la producción de enunciados de este tipo de futuro (35\% frente al 16\% en el grupo menor). Como conclusión, la autora señala que "quizás los niños mayores se proyectan más al futuro. Los niños menores prefieren el uso del presente durativo con la estructura verbal estar más gerundio (69\% en el grupo menor en el 70\% de los niños) (Pandolfi, 190-191).

Resultados similares fueron los de Sebastián (1991)5 , quien observó que ya desde los tres años los niños pueden utilizar prácticamente todas las formas verbales de su lengua, aunque, en algunos casos, con un uso diferente al de los hablantes adultos. Además, encontró que los niños más pequeños, de tres años, tenían dificultad para seleccionar un solo tiempo para sus narraciones y que, cuando lo hacían, elegían el presente, pues sus producciones eran principalmente descripciones de imágenes. Los

4 Peronard 1981, también citada en Villamil, 1991, pp. 212-213. La autora utilizó cuatro categorías de verbos: verbos resultativos, no resultativos, de actividad y de estado.

5 La autora analizó el uso de los tiempos verbales en narraciones orales producidas por niños y adultos españoles, a partir de imágenes. 
niños de 4 y 5 años, en cambio, empleaban predominantemente el pasado y podían reconocer diferencias entre los distintos matices de pretéritos.

Gili Gaya (1960) puntualiza que las formas verbales más utilizadas por los niños corresponden al presente y al pretérito de indicativo, esto por la lógica asociada con la descripción y captación de lo que es visible, tangible o acabado. Algo totalmente distinto ocurre con el empleo de los tiempos futuros en el lenguaje de los niños; según el mismo autor, a causa del carácter eventual de la acción venidera, el empleo del futuro supone la capacidad de abstracción del hablante, razón por lo que aparece tarde y es de uso poco frecuente en el lenguaje infantil.

Los niños usan con preferencia el presente del indicativo con significado de futuro (van, por irán; salto, por saltaré) o bien locuciones perifrásticas en presente, como voy a ir, voy a escribir (por iré, escribiré)... La obligación o el propósito presente de realizar un acto sustituye a las formas del futuro. (Gili Gaya, 2000, 165)

Sebastián et al. (2004) estudiaron la morfología verbal temprana en español y encontraron que los niños comienzan a hacer un uso muy restringido de las formas verbales productivas, lo que, según sus planteamientos, parece sugerir que el aprendizaje de los verbos en español es un aprendizaje fragmentado que se inicia verbo a verbo, con una incorporación muy gradual de nuevas formas al paradigma verbal ${ }^{6}$. En esta misma línea, Tomasello (2010) considera que el desarrollo inicial de la morfología verbal se produce de modo gradual y no generalizado, y, por consiguiente, no habría suficiente evidencia empírica para sostener que los niños pequeños tienen la misma competencia sintáctica de los adultos, como han sostenido algunos investigadores ${ }^{7}$.

Un estudio longitudinal que aborda este tópico es el de Sánchez et al. (2009), cuyo objetivo fue analizar el empleo de los tiempos verbales en las re-narraciones orales y escritas, de niños hispanohablantes de $1^{\circ}$ y $2^{\circ}$ año de educación primaria. Los resultados muestran que ya en primer grado los niños hablantes de español manifiestan un conocimiento de la distribución de los tiempos verbales característicos de la narración,

6 Los autores analizaron el habla de tres sujetos monolingües españoles (edades desde los 1,3 hasta 2;2 años).

7 Es lo que Tomasello denomina hipótesis de las "islas verbales". 
que se apoya en la alternancia del imperfecto/perfecto simple y en la co-ocurrencia de ciertos conectores temporales con tiempos verbales específicos (Sánchez et al., 2009, 113) ${ }^{8}$. Por su parte, Akhtar y Tomasello (1997) realizaron cuatro estudios en los que examinaron la productividad de niños de habla inglesa (de 2 y 3 años), específicamente, el orden de las palabras y la morfología verbal ${ }^{9}$. Según sus resultados, los niños más pequeños no utilizaron ni comprendieron el orden de las palabras; en cambio, los niños más grandes entendieron y utilizaron correctamente el orden de las palabras para marcar agentes y pacientes de los verbos nuevos.

Una pregunta de interés para el estudio de la adquisición y desarrollo de los verbos es la que se plantearon Bernal et al. (2007) y es si los niños pueden utilizar el contexto sintáctico de una palabra desconocida para inferir que es un verbo y que él refiere a la acción. Con la finalidad de responder a esta interrogante, los investigadores realizaron un estudio en niños franceses de 26 meses de edad ${ }^{10}$, cuyos datos muestran que los niños sí fueron capaces de inferir el significado de un verbo nuevo; según los autores, esta eficiencia se debería al uso de diversas estrategias para adquirir nuevas palabras y para identificar la referencia del verbo, tales como el contexto lingüístico significativo, la pragmática de la situación, entre otras. Este mismo hallazgo se puede constatar en la investigación de Naigles (1990), quien concluyó que los niños pueden utilizar la información sintáctica para aprender nuevos verbos; según la autora, si bien es evidente que el aprendizaje verbal es parte de la función de observación de las contingencias del mundo real, la información obtenida de dicha observación es insuficiente para dar cuenta totalmente de la adquisición de vocabulario.

Otros aspectos relativos al verbo, en el plano de la comprensión, están en un trabajo en francés de Barrière et al. (2010), quienes estudiaron la adquisición de la concordancia sujeto-verbo en niños hablantes nativos de francés, de 14 a 30 meses de edad. Sus hallazgos se centran en que

8 Otro objetivo era determinar qué demandas cognitivas pueden incidir en la selección de unidades lingüísticas en el inicio del aprendizaje y generar diferencias respecto de la oralidad.

9 Enseñaron nuevos verbos transitivos con estructuras argumentales, controladas experimentalmente.

10 Los investigadores realizaron un estudio en que a niños franceses de 26 meses de edad les enseñaron verbos nuevos y, enseguida, les presentaron dos instancias, una con un objeto familiar y otro con uno nuevo, junto con la acción realizada; se les pidió que señalaran en la pantalla el objeto que coincidía con el verbo nuevo y los niños respondieron correctamente apuntando hacia la acción familiar (Bernal et al. 2007). 
los hablantes francófonos de 18 meses prefieren las construcciones gramaticales que ponen en juego un sintagma nominal y un verbo irregular en la tercera persona del singular y del plural, y en que a la edad de 30 meses, los niños comprenden las construcciones que contienen un sujeto enclítico de la tercera persona y un verbo que empieza por una vocal, en singular y plural (Barrière et al., 2010, 1441). ${ }^{11}$

Fisher (2002), también en el plano de la comprensión lingüística de verbos, comparó la interpretación de los verbos que realizaban niños de 30 meses, de 40 meses y adultos, y encontró que los niños interpretan los verbos nuevos de acuerdo con el número de argumentos ${ }^{12}$. Los datos obtenidos en su investigación sugieren que la comprensión anticipada de oraciones se ve facilitada por las representaciones mentales abstractas de la estructura de la oración. Concluye que los niños de 3 a 5 años de edad son similares a los adultos en lo que respecta a la producción de verbos nuevos, pues ambos poseen un conjunto de estructuras sintácticas fundamentales o representaciones abstractas que utilizan para interpretar los enunciados.

La gramaticalidad temprana, según López Ornat (1999), es una etapa asociada con el conocimiento, el cambio y el desarrollo constante: "el nuevo conocimiento morfosintáctico es una organización formal que emerge del conocimiento lingüístico anterior, integrándolo y sistematizándolo. Este nuevo conocimiento es productivo: abre la posibilidad de generar infinitas referencias diferentes" (López Ornat, 1999, 519). Como ya se señaló al inicio de este trabajo, los verbos implican la idea de cambio y evolución, y es por ello que se pensó en el estudio de dos fases del niño: los 4,6 meses y los 6,6 meses aproximadamente, ambas como parte de un proceso natural -habitual- que está marcado por la escolaridad y su consiguiente proceso de sociabilización. Es innegable la importancia de los verbos en el lenguaje de todo ser humano, más aún en el del niño, quien en su búsqueda constante del significado de las cosas que lo rodean, intenta con la acción expresar la acción: el comienzo de su

11 Los resultados de este estudio son interesantes, pues contrastan con los hallazgos en comprensión publicados en inglés y español; en este sentido, los niños pequeños franceses parecen entender el contraste entre el singular y el plural, cuando un solo índice está puesto en juego y a una edad mucho más temprana que en estudios previos.

12 Los resultados sugieren que los pequeños utilizan la sintaxis para orientar la interpretación de los verbos nuevos; en este sentido, el estudio apoya varios experimentos previos que muestran que los niños son sensibles a la estructura en la interpretación y que la relación entre sintaxis y semántica se manifiesta ya en ese momento. 
vida requiere de estos significados activos que satisfagan sus deseos y necesidades individuales.

\section{Diseño de la investigación}

La investigación buscó describir y detectar la presencia de tiempos y formas verbales en la producción sintáctica oral de niños, en dos grupos de edad, claramente diferenciados. A continuación, se describen los principales aspectos de la metodología abordada.

\subsection{Objetivos}

\subsubsection{General}

- Identificar qué tiempos verbales utilizan niños, de aproximadamente 4 años, 6 meses a 7 años, cuando narran breves historias.

\subsubsection{Específicos}

- Establecer diferencias en la producción oral de los niños de los dos grupos de la muestra, esto es, niños de 4,6 a 4,11 años y de 6,6 a 7 años.

- Comparar la preponderancia, en ambos grupos, de tiempos verbales en la producción oral y el uso de formas verbales simples y formas verbales compuestas.

- Identificar algunos patrones lingüísticos comunes que permitan entender cómo funciona la temporalidad en el habla y las implicancias que ello conlleva, ya sea dinamismo o estatismo, tiempos simples o frases verbales, entre otros.

\subsection{Hipótesis de trabajo}

Este trabajo empírico está fundamentalmente centrado en la descripción, por lo que la hipótesis, no tan taxativa, es que el grupo de niños más pequeños utilizan preferentemente los tiempos de presente, más que los pretéritos o futuros; en cambio, el grupo de niños más grandes utiliza mayoritariamente los tiempos de pretérito. Ambos grupos usarían escasamente el tiempo futuro y las formas verbales compuestas.

\subsection{Muestra}

La muestra estuvo conformada por un total de diez niños, separados en dos grupos: el grupo A, constituido por tres niños y dos niñas de Pre-

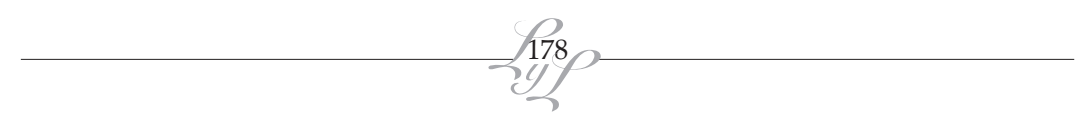


kinder; el grupo B, formado por cinco niños -tres niños y dos niñas- de Primer año Básico. Todos los pequeños pertenecen a la Escuela E-649, de Candelaria, un establecimiento de la Provincia de Concepción con alto riesgo social, y sus edades fluctúan: para el primer grupo, entre los 4,6 años y los 4,11 años; para el segundo grupo, entre los 6,6 años y los 7 años.

\subsection{Procedimiento}

En primer lugar, se solicitó la colaboración al profesor jefe de cada uno de los cursos seleccionados, con el fin de que facilitara la participación de niños con las características solicitadas, tales como tener un rendimiento normal, no tener problemas de lenguaje o de expresión, tampoco tener limitantes para comunicarse con libertad y estar dentro de las edades establecidas para el estudio.

A continuación, se fijaron las sesiones para la grabación individual de cada niño. Para tal cometido, se ambientó la sala de computación de la escuela con los materiales audiovisuales necesarios para el desarrollo de lo planteado, esto es, la pantalla del computador con los Cuentos de la plaza ${ }^{13}$, de los que fueron seleccionados los siguientes cuentos: "Los monos hacen lo que ven", "El viento y el sol”, "Las medias de los flamencos" y "Una trenza tan larga". Se utilizó, también, una grabadora de sonido para registrar la expresión lingüística de cada niño.

Antes de cada sesión de grabación, se destinó un tiempo aproximado de diez minutos para conversar con el niño y estimularlo para la narración -y/o descripción-. Dentro de estas motivaciones estuvo, por ejemplo, la siguiente: "Supe que contabas unas historias de una forma muy linda, me gustaría escucharte"14. A cada grabación por niño se le destinó aproximadamente veinte minutos, contando los tiempos en que el niño quedaba "en blanco", sin hablar absolutamente nada. Por otro lado, hubo niños que quisieron narrar más de los dos cuentos planeados, sin embargo, sólo se computaron dos de ellos. El observador evitó su

13 Los cuentos de la plaza es un programa computacional adaptado para niños de aproximadamente cuatro a siete años. Están conformados por imágenes correspondientes a historias con una sucesión temporal; además, cuenta con algunas situaciones de movimiento y de sonidos ambientales. En las grabaciones, se registró el relato o descripción de lo que cada niño iba observando en pantalla; la adecuación de cada imagen en el computador estuvo mediada por el tiempo que necesitó cada niño para "hacer" su cuento. Se habían establecido previamente, además, otros cuentos, pero no fue fructífero lo obtenido mediante ellos, por lo que fueron obviados del cómputo final.

14 Para la entrevista, se tomó en consideración la metodología explicada en Echeverría (1986). 
intervención durante el relato del niño; en su lugar, sólo se limitó a colaborar con expresiones tales como "¿Qué ves ahí?", "cuéntame todo lo que quieras", cuando el niño no emitía ningún tipo de enunciado en un tiempo bastante prolongado.

Luego de obtenidas las producciones lingüísticas, se procedió a la transcripción de todas las expresiones del niño, con un foco en el objeto de estudio, esto es, en los verbos y tiempos utilizados. Enseguida, se estableció como instrumento de análisis la agrupación de datos en matrices con las casillas necesarias para destacar los rasgos a observar, clasificar y describir (según la taxonomía de Gili Gaya, 2000).

\section{Resultados}

Los resultados que se presentan en este apartado corresponden al detalle de los tiempos y formas verbales observados en cada uno de los niños y en los dos grupos con los que se trabajó (A, preescolares; B, escolares). En lo referente a tiempos verbales, se consideró el presente, pretérito, condicional, futuro, por ser tiempos ya estudiados en investigaciones previas (Peronard, 1981 y Pandolfi, 1988) y porque son los tiempos verbales con mayor ocurrencia en el presente trabajo.

\subsection{Resultados Grupo A}

En la tabla 1 se presentan los tiempos verbales constatados en la producción lingüística de los niños más pequeños, esto es, en los niños de pre-kinder.

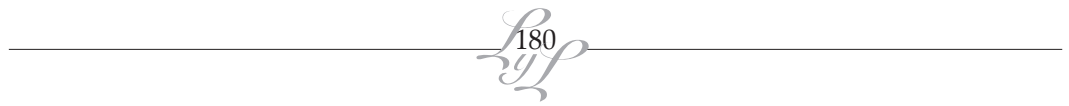




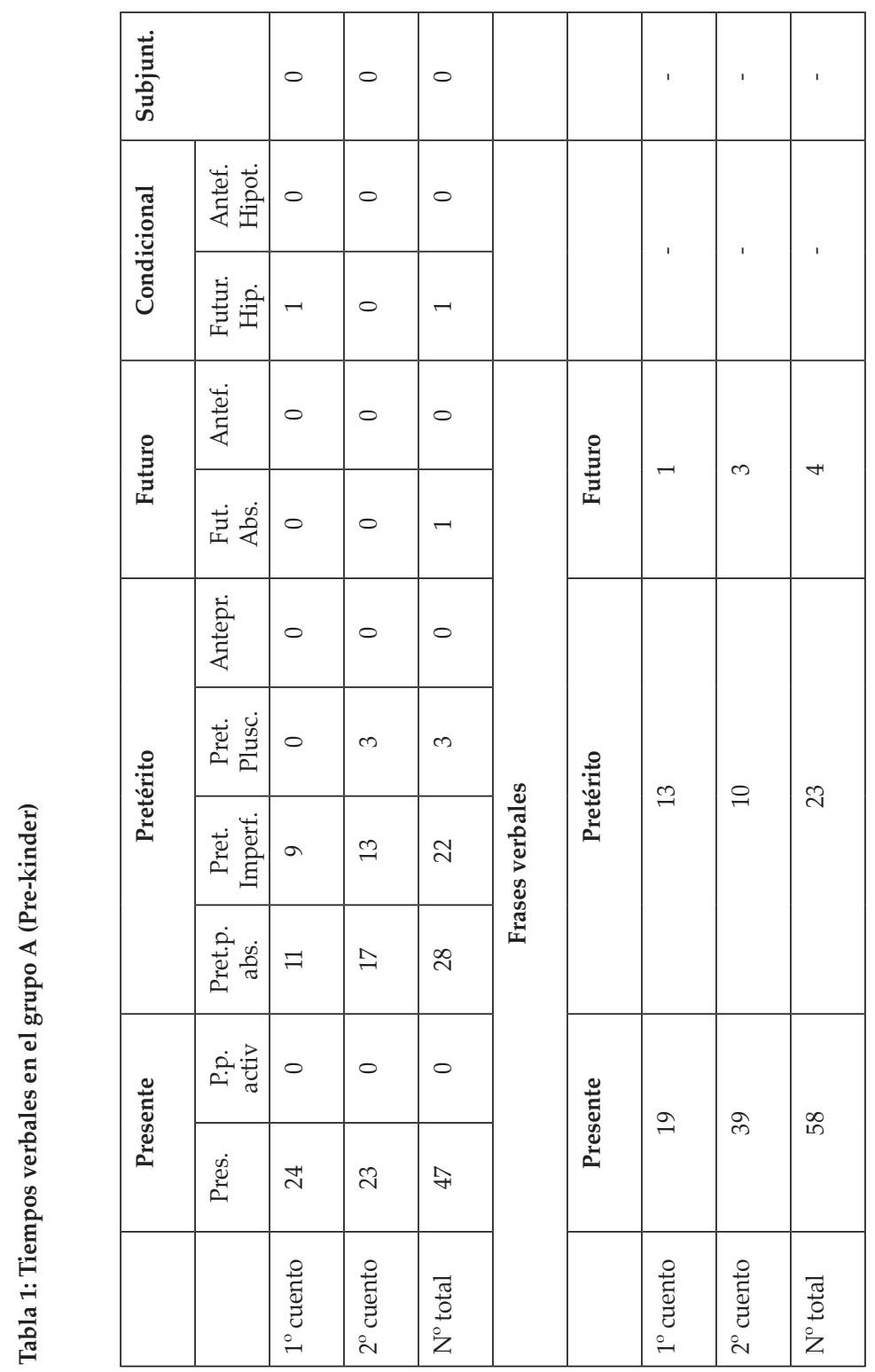




\section{Gráfico 1: Tiempos verbales en el Grupo A}

国 Pres. $\square$ Pret. $\square$ Fut. $\square$ Cond.

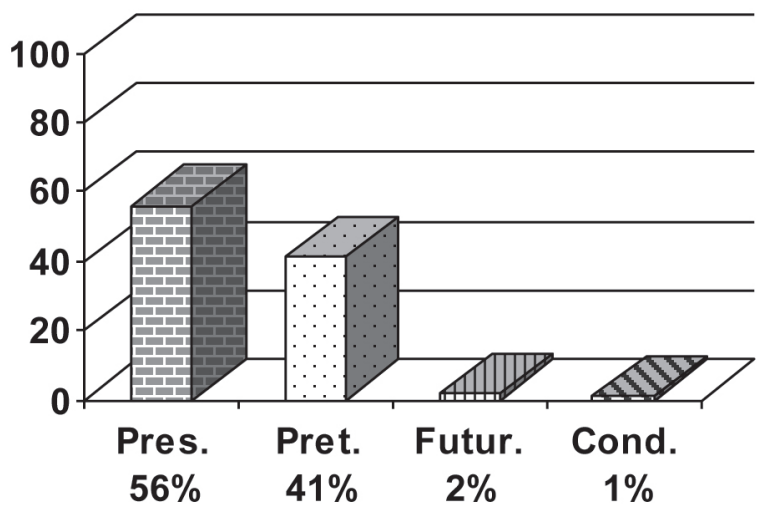

Lo presentado en el gráfico 1 permite constatar lo referido en la bibliografía especializada, acerca de que el tiempo con mayor presencia en la producción lingüística de los niños durante sus primeras etapas de desarrollo es el presente. Frente a los dos cuentos narrados, el niño evidenció un mayor uso de este tiempo, con un 56\%, equivalente al porcentaje resultante entre el número de ocurrencias verbales del tiempo y el número total de formas verbales presentes en la comunicación lingüística de los niños del estudio. El segundo tiempo más utilizado fue el pretérito ${ }^{15}$ con un $41 \%$; luego el futuro, con un $2 \%$, y, finalmente, el condicional con un $1 \%$ del total verbal. Parece pertinente mencionar que ninguno de los tiempos del modo subjuntivo e imperativo fue presentado en el habla de los niños observados, ése es el motivo de por qué se ha informado sólo sobre el modo indicativo.

\subsection{Resultados Grupo B}

En la tabla 2 se muestran los tiempos verbales observados en la narración de historias de los niños de primer año básico.

15 Aquí se prefirió la generalidad de los términos verbales -presente, pretérito, futuro, condicionalpara hacer referencia a la temporalidad en cuanto al ayer, hoy y mañana, en términos globales.

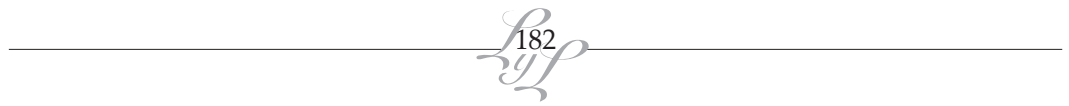




\begin{tabular}{|c|c|c|c|c|c|c|c|c|c|}
\hline \multicolumn{2}{|l|}{$\begin{array}{l}\frac{\overrightarrow{3}}{3} \\
\frac{3}{0} \\
\omega\end{array}$} & 0 & 0 & 0 & & & ' & 1 & ' \\
\hline \multirow{2}{*}{ 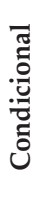 } & 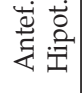 & 0 & 0 & 0 & & & \multirow{2}{*}{ ' } & \multirow{2}{*}{ ' } & \multirow{2}{*}{ ' } \\
\hline & 壱豈 & - & 0 & - & & & & & \\
\hline \multirow{2}{*}{$\underset{\Xi}{\stackrel{ }{\Xi}}$} & $\begin{array}{l}\text { 峁 } \\
\dot{\Xi}\end{array}$ & 0 & - & - & \multirow{6}{*}{\multicolumn{2}{|c|}{ 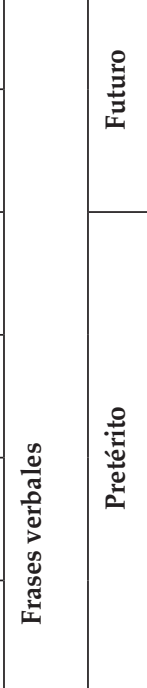 }} & \multirow{2}{*}{$N$} & \multirow{2}{*}{$N$} & \multirow{2}{*}{ H } \\
\hline & 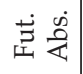 & - & 0 & - & & & & & \\
\hline \multirow{4}{*}{ 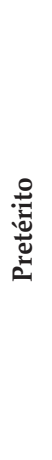 } & 葶 & 0 & 0 & 0 & & & \multirow{4}{*}{$\exists$} & \multirow{4}{*}{$\stackrel{1}{\sim}$} & \multirow{4}{*}{ ते } \\
\hline & 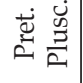 & $N$ & $N$ & + & & & & & \\
\hline & 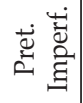 & $\stackrel{10}{m}$ & $\stackrel{\infty}{\infty}$ & $\propto$ & & & & & \\
\hline & 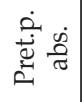 & $\ddot{\sim}$ & ন & f & & & & & \\
\hline \multirow{2}{*}{ 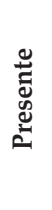 } & $\underset{\sim}{\dot{2}}$ & 0 & 0 & 0 & & \multirow{2}{*}{ 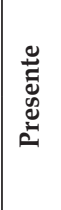 } & \multirow{2}{*}{ নे } & \multirow{2}{*}{$\stackrel{\bullet}{\sim}$} & \multirow{2}{*}{ \& } \\
\hline & $\stackrel{\dot{\Xi}}{\varrho}$ & 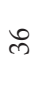 & भे & $\stackrel{\infty}{\infty}$ & & & & & \\
\hline & & 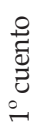 & 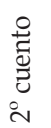 & $\begin{array}{l}\text { 푬 } \\
\text { ○े } \\
\text { Z }\end{array}$ & & & 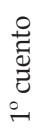 & 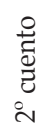 & 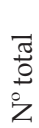 \\
\hline
\end{tabular}




\section{Gráfico 2: Tiempos verbales en el Grupo B}

$\square$ Pret. $⿴$ Pres. $\square$ Fut. \$ Cond.

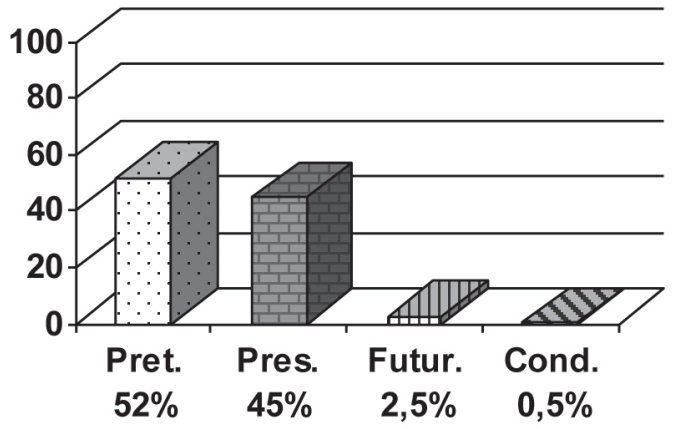

En el gráfico 2, se puede observar que el tiempo privilegiado por los niños de Primero Básico para narrar las historias, a diferencia del grupo A, fue el pretérito, con un 52\%; seguido por el presente, con un $45 \%$; el futuro, con un $2,5 \% \mathrm{y}$, por último, el condicional, con un $0,5 \%$. Los datos permiten señalar que el pretérito es de aparición tardía y, por lo tanto, su desarrollo y frecuencia es mayor a medida que el niño aumenta su edad.

\subsection{Resultados por cada tiempo verbal}

Tabla 3: Recuento de palabras y total de tiempos verbales empleados por ambos grupos.

\begin{tabular}{|c|c|c|c|c|}
\hline & \multicolumn{2}{|c|}{ Grupo A } & \multicolumn{2}{c|}{ Grupo B } \\
\hline & $N^{\circ}$ & $\%$ & $N^{\circ}$ & $\%$ \\
\hline Palabras Totales & 943 & $100 \%$ & 1504 & $100 \%$ \\
\hline $\begin{array}{c}\text { Total de formas } \\
\text { verbales }\end{array}$ & 187 & $19,8 \%$ & 288 & $19,1 \%$ \\
\hline \multicolumn{2}{|c|}{ Tiempos verbales } \\
\hline \begin{tabular}{c} 
Tiempos presente \\
\hline
\end{tabular} & 105 & $56 \%$ & 130 & 45 \\
\hline Tiempos pretéritos & 76 & $41 \%$ & 151 & 52 \\
\hline Tiempos futuro & 05 & $02 \%$ & 06 & 2,5 \\
\hline $\begin{array}{c}\text { Tiempos } \\
\text { condicional }\end{array}$ & 01 & $01 \%$ & 01 & 0,5 \\
\hline
\end{tabular}


En la tabla 3, se presenta el porcentaje de formas verbales empleadas por los niños de acuerdo con el número total de palabras que requirió para su expresión lingüística; también se detalla el total de cada uno de los tiempos verbales y el porcentaje correspondiente. En relación con la misma, conviene destacar el gran incremento en el número de palabras generales por grupo, desde Pre-kinder a Primero Básico; sin embargo, el porcentaje que relaciona verbos por el número total de palabras es mayor en el grupo A, con un $19.8 \%$, que en el grupo B, con un $19.1 \%$, lo que haría suponer que el lenguaje del niño preescolar es más dinámico, verbalmente hablando, que el del niño en su primer año de escolaridad. Se podría interpretar este hecho asociado a la inquietud por la exploración, por la acción propia de quien está en búsqueda de lo nuevo: se afianzaría con esto la idea del desarrollo del niño en sus primeros años. Por último, en cuanto a las formas del verbo, las más utilizadas fueron las simples, pero no se debe obviar el hecho de que en ambas etapas los niños utilizaron muchas frases verbales o conjugaciones perifrásticas para sus realizaciones lingüísticas: un $45.4 \%$ para el grupo A y un $26.3 \%$ para el grupo B.

Gráfico 3: Comparación entre los cuatro tiempos verbales en los dos grupos

田 Grupo A $\boxminus$ Grupo B

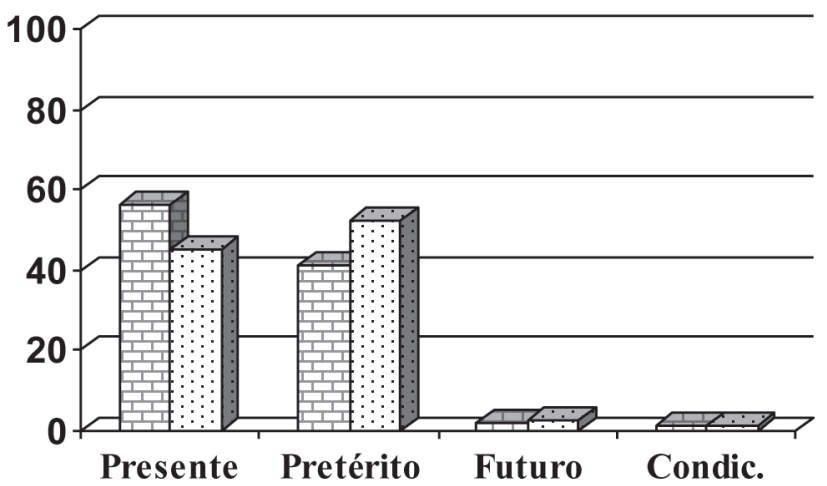


En el gráfico 3, se puede observar el contraste entre los resultados obtenidos por el primer y segundo grupo de niños, en cuanto a los cuatro tiempos verbales Los dos tiempos mayormente utilizados para las narraciones fueron el presente y el pretérito, con una escasa aparición de los futuros y condicionales.

\section{Discusiones y conclusiones}

Luego de expuesto este estudio, es posible afirmar que la hipótesis de trabajo (descriptiva) se vio confirmada por los datos trabajados y analizados a partir de la muestra de lenguaje oral de los niños. El grupo de menor edad manifestó un mayor uso del tiempo presente, seguido por el pretérito; por su parte, el grupo de escolares utilizó preferentemente el tiempo pretérito, seguido por el presente. Tal como se había señalado previamente, se constató un mayor uso del pretérito imperfecto que del perfecto. Siguiendo a Gili Gaya (1960, 2000), en ambos grupos, la utilización del futuro fue escasa, probablemente debido a la abstracción que este tiempo verbal implica y a la edad precoz de los niños. En cuanto a las frases verbales, se pudo constatar un privilegio por el uso de las formas verbales simples más que por las compuestas, exceptuando la utilización de perífrasis para hacer alusión al tiempo futuro, como en "va a saltar", "se va a ir para la casa" (en lugar de saltará o irá).

Otro aspecto importante de destacar es que se observó un aumento en el número de palabras al diferenciar la producción de ambos grupos. Este hallazgo se relaciona con los obtenidos por Sánchez et al. (2009) quienes, al diferenciar las producciones de primero y segundo grado, encontraron que los avances más importantes se dieron en torno a la extensión de las producciones y al uso fundamental de los tiempos centrales de la narración, esto es, el pretérito perfecto simple y el imperfecto (Sánchez et al., 2009, 112).

Es de suma importancia destacar que, de acuerdo con los lineamientos del presente estudio, se considera que el niño en sus primeros años no se encuentra deprivado lingüísticamente, a pesar de la existencia de determinadas condicionantes externas, específicamente atingentes a la muestra seleccionada, que hubiesen podido influir en su desarrollo, tales como carencias económicas, socioculturales y vulnerabilidad del entorno más cercano. En los grupos observados, no se registró ningún caso de una conjugación que no correspondiese al verbo; llama la atención este hecho y, más aún, surge la pregunta ¿en qué momento se hace más difícil 
la comunicación o una expresión eficiente del niño en riesgo social? Es por todos sabido que la gran mayoría de los niños (as) con problemas socioeconómicos serios presenta dificultades para establecer una comunicación eficaz y aceptable, según las diferentes reglas lingüísticas. De igual forma y en relación con los verbos, se presenta la siguiente interrogante, que podría ser respondida en una investigación futura: ¿los problemas surgen cuando el niño ya va adoptando o haciendo uso del subjuntivo? Generalizando, se puede señalar que el niño sólo utiliza algunos tiempos del modo indicativo y, más aún, sorprende totalmente el hecho de que solamente cinco formas en Pre-kinder y seis en Primer año Básico correspondieran al tiempo futuro. En este punto conviene retomar a Gili Gaya (2000), quien señaló que este tiempo es de uso poco frecuente en el lenguaje infantil, debido a la abstracción que implica y a la aglutinación histórico-lingüística de que fue objeto (cantar has: cantarás).

No estaba dentro de los propósitos investigativos analizar la diversidad verbal utilizada por el niño, esto es, número de verbos en infinitivo disponibles en su léxico para las conjugaciones; sin embargo, es preciso mencionar que hubo algunos niños que utilizaron el "haber" y el "estar" como fuentes recurrentes para su expresión. A continuación, se presentan algunas transcripciones que ilustran este fenómeno:

\section{Ejemplo 1:}

Hay viento. Hay viento y hay un hombre.

Hay un árbol, un sol y un hombre. Se está sacando la capa y hay viento. Se sacó la capa y hay un árbol y hay un sol.

Hay viento, se está sacando la capa y está jugando con ella.

Y después hay otra vez un sol, un árbol y un hombre que se sacó la capa.

(Extracto de transcripción de Daniel, un niño de Pre-kinder frente al cuento "El viento y el sol").

\section{Ejemplo 2:}

Había una vez, ¿qué es lo que es? ¿Un caballero? (pregunta el niño, sí se le responde). Había una vez un caballero que $i b a$, iba pa' la casa y iba con hartos gorros en la caeza. Y había un sol.

Había una vez un caballero que estaba acostao al árbol del tronco del árbol. 
Y había un caballero que se estaba tocando el gorro y estaba un sol, un árbol y un volcán. Y había un caballero que tenía el deo' así (muestra su dedo); así, datrás de él había un mono, estaba arría y tenía un gorro en la mano y había un volcán. Le dice... había un caballero que tenía el pie levantao' pa' arría y había un mono que estaba haciendo lo mismo, parece...

(Extracto de transcripción de "Los monos hacen lo que ven", de Nicolás, un niño de Primer año Básico").

No obstante la aparente reiteración y simplicidad anterior, hubo un caso de una niña de primer año, que dentro de sus cincuenta y cinco formas verbales empleadas en ambos cuentos, treinta y seis correspondieron a verbos diferentes ${ }^{16}$. Un intento de explicación para un buen desempeño en producción se puede observar en la reflexión de Bassano (2010), quien sostiene que a la edad de tres años, el niño ya está bien equipado para iniciar su largo camino en el proceso de escolarización y que, con su asombrosa capacidad para aprender e interactuar con el medio ambiente, ha establecido las bases del léxico de los verbos (desarrollado después de los nombres) y puede producir correctamente las más usuales formas verbales, como aquellas pertenecientes al tiempo presente, pasado y futuro cercano ${ }^{17}$.

Es de relevancia extrema el que los niños observados manifestaron un deseo por comunicarse y eso es válido para el educador, puesto que hace pensar que algo -o mucho- se puede hacer para ayudar a estos niños y prepararlos para que en el futuro no manifiesten problemas en su expresión oral y escrita; eso sí, debe reforzarse en sus primeros años de escolaridad, cuando el caudal lingüístico se está manifestando en toda su plenitud. Nuevamente, se confirma que existe una capacidad innata para el lenguaje y que el niño en esta etapa está en un momento todavía de expansión, de crecimiento personal y de desarrollo. Está en manos de padres y educadores colaborar para que este floreciente desarrollo continúe a lo largo de toda la vida del niño.

16 Los verbos usados por la niña fueron: haber, hacer, ir llevar, andar, pasar, saltar, jugar, decir, comer, saludar, tocar, mostrar, tener, parecer, enojar poner, dejar, mirar, bailar, echar, llegar, perseguir, romper, lavar, botar, pegar, ensayar, descansar, correr, observar, sacar, conversar, reír, soplar, bañar(se).

17 Bassano (2010) analizó la adquisición espontánea (interacción con el medio ambiente) de los verbos en francés, en niños de 1 a 3 años. 37. 


\section{Referencias}

Aitchison, J.1992. Elmamífero articulado. Introduccióna la Psicolingüística. Madrid: Alianza.

Akhtar, N. y Tomasello, M. 1997. “Young children's productivity with word order and verb morphology". Developmental Psychology Vol. 33 (6), Nov. 1997, 952-965.

Barrière, I.; Legendre, G.; Nazzi, T.; Goyet, L. y Kresh, S. 2010. "L'acquisition de l'accord sujet-verbe par les jeunes francophones natifs entre 14 et 30 mois: préférence, compréhension et environnement linguistique". Neveu F., Muni Toke V., Durand J., Klingler T., Mondada L., y Prévost S. (éds.), Congrès Mondial de Linguistique Française CMLF 2010, Paris 2010, Institut de Linguistique Française, 1429-1443.

Bassano, D. 2010. “L'acquisition des verbes en français: Un exemple de l'interface lexique/grammaire". Synergies France 6, 27-39.

Bernal, S.; Lidz, J.; Waxman, S.; Dutat, M. y Christophe, A. 2005. Role of syntactic cues in verb acquisition: results from 23-month old infants. Paper presented at the Xth International Congress for the Study of Child Language, Berlin, Allemagne.

; ___ Millotte, S. y Christophe, A. 2007. "Syntax Constrains the Acquisition of Verb Meaning". Language learning and development 3 (4), 325-341.

Chomsky, N. 1965. Aspects of the Theory of Syntax. MIT Press, Cambridge, Mass.

Echeverría, M. 1978. Desarrollo de la comprensión infantil de la sintaxis española. Concepción: Ediciones Universidad de Concepción.

1984. “El desarrollo del lenguaje y su incidencia en el aprendizaje". RLA 22, 17-26. 
Ezeizabarrena, M. 2009. Adquisición de la morfología verbal en euskera y castellano por niños bilingües. Tesis doctoral, Servicio Editorial, Universidad del País Vasco, 329 páginas.

Fisher, C. 2002. "Structural limits on verb mapping: the role of abstract structure in 2.5-year-olds' interpretations of novel verbs". Developmental Science 5, 56-65.

Gili Gaya, S. 1960. Funciones gramaticales en el habla infantil. Río Piedras, P. R: Universidad de Puerto Rico. 2000. Curso Superior de Sintaxis española. Barcelona: Vox.

Karmiloff-Smith, A. 1994. Más allá de la modularidad. Madrid: Alianza.

López Ornat, S., Fernández, A., Gallo, P. y Mariscal, S. 1994. La adquisición de la lengua española. Madrid: Siglo XXI.

López Ornat, S. 1999. "La adquisición del lenguaje. Nuevas perspectivas". En M. de Vega y F. Cuetos (Eds.) Psicolingüística del español. Madrid: Trotta.

Meisel, J. 1990. "Inflection: subjects and subject verb agreement in early child language". Meisel (ed). Two first languages. Early grammatical development in bilingual children, Dordrecht, Foris, 237-300.

Naigles, L. 1990. Children use syntax to learn verb meanings. Journal of Child Language 17, 357-374.

Pandolfi, A. M. 1988. "La sintaxis del niño en dos etapas de su desarrollo". Revista Intercontinental de Psicología y Educación, Volumen 1, 2, 185-203.

Parisse, C. 2005. "New perspectives on language development and the innateness of grammatical knowledge". Language Sciences 2, 383-401.

Peronard, M. 1981. La expresión temporal en las primeras etapas de la adquisición de la lengua materna. Ponencia presentada en el $6^{\circ}$ Congreso ALFAL, Arizona.

Piaget, J. (1986). Seis estudios de Psicología. Bs. As. Argentina: Ariel, S.A.

Sánchez, V.; Silva, M. y Borzone, A. 2009. “El empleo de los tiempos verbales en la re-narración. Un estudio de las 
producciones orales y escritas de niños pequeños". Boletín de Lingüística XXI/32, 95-117.

Sebastián, M. 1989. Tiempo y aspecto en el lenguaje infantil. Tesis doctoral, Madrid, UAM.

Sebastián, E. 1991. “El desarrollo del sistema de referencia temporal en español: un paseo por la morfología verbal". Anales de Psicología 7, 2, 181-196.

; Soto, P. y Mueller Gathercole, V. 2004. “La morfología verbal temprana en español". Anuario de Psicología, Vol. 35, 2, 203-220.

Tomasello, M. 2000. "Do young children have adult syntactic competence?" Cognition 74, 209-253.

Villamil, B. 1991. "La adquisición de aspecto y tiempo en niños puertorriqueños entre las edades de 1;10 a 3;2 años". En López Morales, H. Puerto Rico: Editorial de la Universidad de Puerto Rico, 199-212.

Vygotski, L. S. 2001. Obras escogidas II. Madrid: Machado libros, $2^{\mathrm{a}}$ Edición. 